\title{
Drivers, Challenges, and Integration of Health 4.0 Societal Engagement: Evidence from Turkey
}

\author{
Ozum Egilmez1 $\odot$, Gozde Koca2 $\odot$
}

\begin{abstract}
In Turkey, a novel concept like Health 4.0 is a potential candidate seeking a solution. This paper aims to identify the scope of Health 4.0 via the perceptions gathered from appropriate vignettes with the focus of loT stand and with the help of a qualitative approach in the first phase of the hybrid methodology. In the first phase of the study, the authors revealed the drivers and challenges of Health 4.0 by asking for the scope and awareness of Health 4.0. In the second phase of the study, the given replies to the vignettes (possible real-life scenarios) were classified into four main criteria that serve several challenges towards the adoption of Health 4.0, which were evaluated by the MACBETH (Measuring Attractiveness by a Category-Based Evaluation Technique) approach to identify main and sub-challenges towards the concept. In doing so, by analyzing in a multicriteria method, results would help to recheck and undermine the current debates around the Health 4.0 concept, helping to form many applicability levels in the future. The results revealed that security was the most important criteria followed by education, confidentiality, and the politics/manageability criteria as being the least important challenge.
\end{abstract}

\section{Keywords}

Health 4.0, Sustainable Integration, Multi-Criteria Decision Making, Strategic Management, MACBETH

\section{Introduction}

Todays" wisdom is "Change is manageable," which has already progressed in our lives. This wisdom is in the word of the revolution itself that Industry 4.0, the novelist enabled a new vision in numerous industries and areas (Liao et al., 2017) As it has mostly impacted the manufacturing sector already, there is a forthcoming impact not only economically but also socially in general (Xu and Chen, 2017; Xu et al., 2018). Industry 4.0 vision, if affordable and accessible, would change the prosperity of society. However, we all need to adopt the digital world by defining the drivers and challenges that are covered by the term Industry 4.0- the

1 Corresponding Author: Ozum Egilmez (Asst. Prof. Dr.), Bilecik Seyh Edebali University, Faculties of Economics and Administrative Sciences, Department of Business Administration, Bilecik, Turkey. E-mail: ozum.egilmez@bilecik.edu.tr ORCID: 0000-0001-5251-5629

2 Gozde Koca (Asst. Prof. Dr.), Bilecik Seyh Edebali University, Faculties of Economics and Administrative Sciences, Department of Business Administration, Bilecik, Turkey. E-mail: gozde.koca@bilecik.edu.tr ORCID: 0000-0001-6847-6812

To cite this article: Egilmez, O., \& Koca, G. (2021). Drivers, Challenges, and Integration of Health 4.0 Societal Engagement: Evidence from Turkey. Istanbul Business Research. Advance online publication. http://doi.org/10.26650/ibr.2021.51.0131 
digital infrastructure that enables benefits from the potential opportunities (Tortorella et al., 2020; Hathaliya and Tanwar, 2020). Every change has its resistance; therefore, we need to have a better understanding of Industry 4.0 areas which will also help us to have a manageable future in a collective approach.

One of the main concepts derived from Industry 4.0, being a bridge between social and economic conditions, is Health 4.0 approach. It has also taken its roots from innovation; however, it has a broader scope in the societal area (Wehde, 2019). Health 4.0 also means an essential change in the relations of stakeholders. In other words, it is not merely based on the infrastructure of Industry 4.0, but also an embedded version of consumers and providers. To be able to adapt, the providers and consumers need to work closely. By doing this, the opportunities and the challenges can be altered, and the socio-economic aspects ensured (Nair and Dreyfus, 2018). For instance, Health 4.0 is one of the central veins of human life that needs a better understanding of both growing and emerging countries.

It is the purpose of this research to assess the awareness of the Health 4.0 concept by revealing the drivers, challenges via the basis of Industry 4.0, and to frame strategic logic for better integration in the future in the context of individual perspectives. This present work makes several contributions to understand Health 4.0, which is a relatively novel concept for Turkey. As Health 4.0 is understudied (in Turkey) to date, such a dynamic is needed to investigate the multiple development levels (economic, social, and technological), as suggested in the research.

The second contribution of this work; providing a general framework of Health 4.0 addressing practitioners, decision-makers, and all stakeholders who are engaging in the Health 4.0 concept as well as academics as the current situation is the subject is understudied. Future agenda is considerably occupied for an emerging and aging country, Turkey, should act proactively as similar challenges are just several steps away from population aging countries are facing today (Meyer, Torssander, Talbäck, and Modig, 2019).

Due to scarcity of studies that investigate Health 4.0 and the drivers and challenges in emerging economies, two research questions are proposed:

RQ1: What are the drivers and challenges to achieve a possible healthcare system? (Implicit process and outcomes- a definition of the ecosystem of Health 4.0 and awareness of Health 4.0) and RQ2: What factors exist in Turkey that leads to meaningful outcomes in terms of Health 4.0? (e.g., legal, technological, societal, political? etc.)

To answer these questions, two studies are planned in a hybrid manner. This study explores the consequences faced by an individual who is concerned with the healthcare of the parents through vignettes in a qualitative study (RQ1), and with the findings of study 1, a 
quantitative study (RQ2) was conducted to reveal the embedded knowledge in Health 4.0. These consequences are reflected in terms of individual, institutional, and societal levels of thought that may enable to sequence design of Health 4.0 drives, challenges, and integration within the given country by raising prospective alternatives of healthcare. The use of the hybrid approach and the factors resulting to guide efforts and resources which are especially important in an emerging economy concept that is to be counted the importance of this work.

\section{Health 4.0 by the Roots of Industry 4.0}

There is no doubt that as the population of the world is proliferating with a high life expectancy rate even in emerging or developed countries. According to OECD, the life expectancy of people over 65 and 80 years is increasing as well. As it may seem a development at first glance, it is also a challenge for the countries and societies to be managed due to the lower fertility rates. People getting older with fewer babies being born is considered in the old-age dependency ratio concept, which is predicted to increase in the coming 30 years. With the increase of this ratio, the concern of health care arises, the hospital beds, the average length of stay in the hospital, outpatient care, long term care, qualified care workers, etc., issues occur. Therefore, Healthcare is an economic burden for the countries needed to be projected to maintain the wealth of society. There is no denying that healthcare spending is dependent on aging, so health costs are to be planned with much greater attention. Even though health care spending is a burden, on the other hand, we need to consider it as a growing economy as well. It is a challenge for the nations' budget but also an opportunity for commercial industries and individuals.

Here where Industry 4.0 contributes to the health care system. Bearing in mind that technology not only reduces costs, but it is also a vision, not a trend to be precisely defined. Reducing administrative costs, reducing the time spending on documentation or diagnosing or operation on one hand, but creating value-added services for the individual for a betterquality life on the other. It is hard to give a precise definition for the complex nature of new manufacturing technology affecting the long term health of society because of the many facets. One needs to stress that if one considers Health 4.0 an utmost importance, surely that will serve better for our coming years. To be able to do that, its broad meaning and vision as a life philosophy needed to be understood.

As a vision, Health 4.0 can be defined in a value chain, not just framed by hospital, insurance, and pharmaceutical dimensions. If you fragment the care system from hospitals, there are many segments (all can refer to an opportunity) such as social care, psychotherapists, day clinics, community nurse nursing homes or informal carers, etc. Through revolution 4.0, communication became the utmost priority to create value in any process as in the health care industry. The vision started with the technologies powered by industrial revolutions. The 
range of equipment, medicine, healthcare, health logistics, financial, and social systems are all correlated with the Industrial revolutions (American Institution for Medical and Biological Engineering, 2019).

Table 1

Possible Correlation of the Industry Revolutions and Healthcare Technologies

\begin{tabular}{ll}
\hline $\begin{array}{l}\text { Industry } 1.0 \\
\text { Mechanization }\end{array}$ & $\begin{array}{l}\text { flexible tube stethoscope (the 1840s), piston syringe (1850s), and portable clinical } \\
\text { thermometer (1860s). }\end{array}$ \\
Industry 2.0 & such as X-ray imaging (the 1890s), sphygmomanometer (1890s), electrocardiograph \\
Electrification & $(1900 \mathrm{~s})$. \\
& brightness mode ultrasonography (the 1960s), implantable pacemaker (1970s), X-ray \\
Industry 3.0 & computed tomography (1970s), magnetic resonance imaging (1980s), artificial heart \\
Automation & (1980s), Positron Emission Tomography (1980s), \\
Industry 4.0 & cyber-physical systems, IoT and services, AI, big data, robotics, bio-three dimensional \\
Cyber-Physical Systems & (3-D) printing, connected wearable devices \\
\hline
\end{tabular}

Source: Adapted from Pang et al. (2018)

The embedded relation of Industry and Health revolutions diverge us to identify the drivers that can be investigated on the same basis.

\section{Drivers of Health 4.0}

The drivers of Industry 4.0 are established in a working paper as a literature review by the Audi Foundation Professorship at the Technical University of Dortmund in 2015 (Hermann, Pentek, and Otto, 2016). Interoperability occurs as the first driver that enables machine and human connection over IoT and IoS, Cyber-Physical systems, and also Smart Factory as in Industry 4.0. It is crucial that all levels of information should flow smoothly so that the entire system can work. Thus, providing all relevant data to meaningful information such as medical devices to reach more accurate data to enable better service or diagnosis as in Health 4.0 (Alshurafa et al., 2013). Interoperability is the leading enabler of the pervasive and preventive healthcare notion of Health 4.0. By wearing a device, the connection can be stabled and data forms the health records can be distributed. Therefore, data analytics present our healthcare services and capabilities with more possibilities. Not only with real time information but also with the cyber-physical system sensing information via scenarios will telehealth and remote caring under the scope of pervasive and preventive healthcare be provided (Pang, Yang, Khedri, and Zhang, 2018).

Hence there occurs another new issue in medicine and human society, dependence on the real-time data and analyzing and creating personal healthcare records combined with other biosystems (Yang and Cui, 2018). This scope is out of the authors' professional title (biodesign and manufacturing focus on that). Instead, the authors focus on the consciousnessraising part of human society on the individual level, presupposition, individuals facing more personalized and precise healthcare (diagnosis and treatment) via interoperability of IoT and 
Cyber-Physical Systems. This view is also identified as the real-time capability driver of Industry- Health 4.0 so forth. Real-time capability is related to the possible out-of -hospital treatment where patients are given the exact amount of medication required with maximum therapy but minimum side effects. Personalized medicine, smart pharmaceuticals, and supply chain management can only be implement via clearly defined real-time capability.

The customer-oriented view is also a principle of Healthcare. Combination of big data, collecting data from all wearable sensors, smart inhalers, insulin pens around the world, enable knowledge on diseases, their progress, and cures. Therefore prevention, personalized care, precise, predictive, and participatory health concepts are all combined in the service-orientation driver. This driver enables the pharmaceutical companies, algorithms (e.g., Google), and service providers $(5 \mathrm{G})$ to act in health care vendors distributing and leveraging service aggregation around the world. Modularity is the other driver referring to the flexibility to adapt to changing requirements by replacing and individual modules helping to create new functionalities for stakeholders (e.g., Google software as edge clouds). In doing so, decentralized decision making to reduce latency and enhance security supported. In recent years most European countries included Turkey, launched the e-Health system to enable patients and health institutions to reach the information. However, it is not connected to any other network yet, but the accessibility of your medical records is a huge step (e.g., Turkey E-Health). It can be foreseen that the system in England is going to be distributed to many parties such as patients, professionals, and formal and informal carers who are using sensors, smart devices, smartphones, applications, and cyber-physical systems increasingly (NIB, 2014). For instance, when the new applications, designs, and solutions emerge in one country, isomorphism interoperate. However, the norms and the standards should be considered to each country's cultural values as they are the bricks building the revolutions (e.g., Industry/Health 4.0) on a reliable basis - this the hypothesis to be systematically checked and explained not in this paper but further (Michael, K., Gokyer, D., and Abbas, S., 2018). 


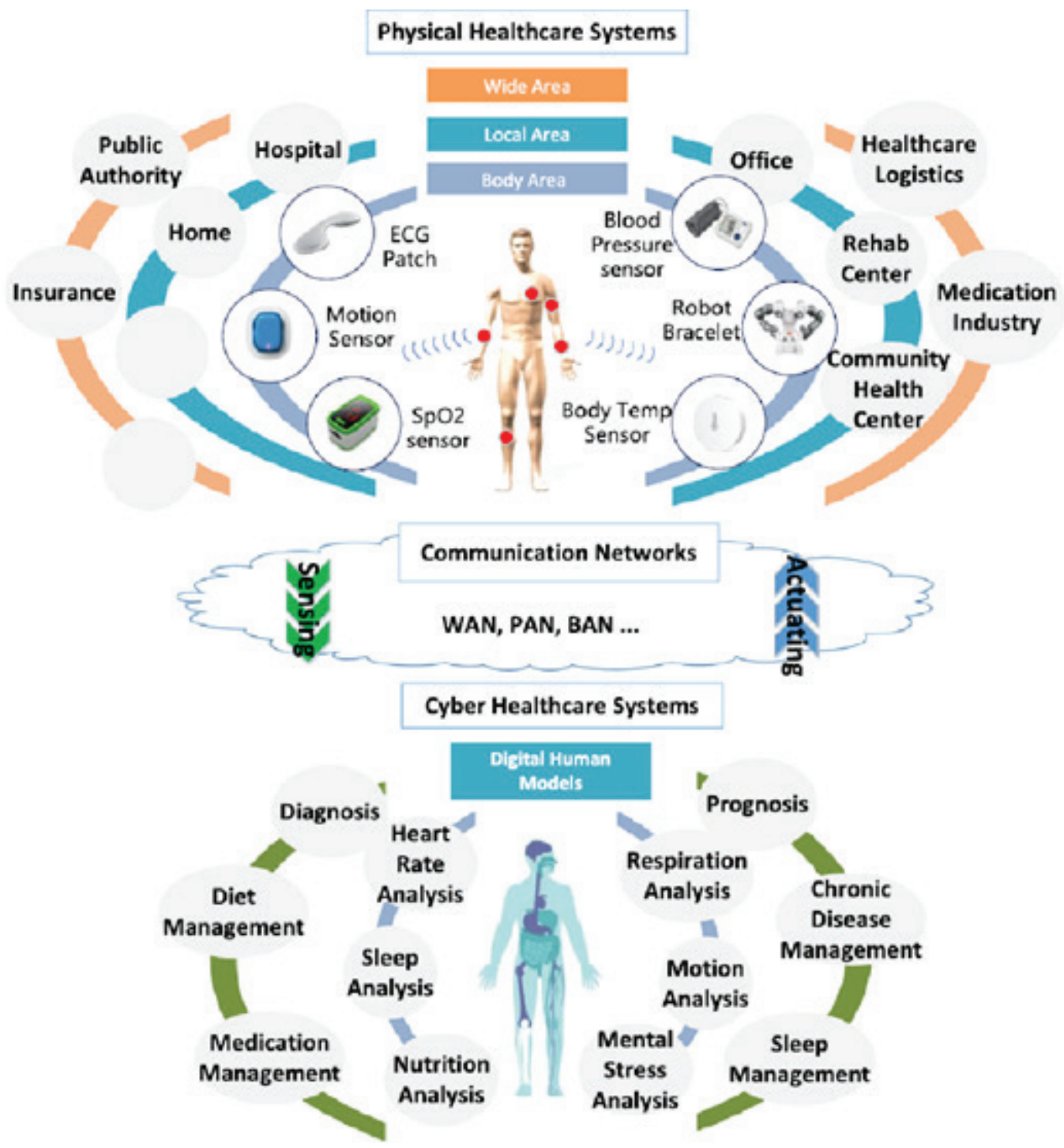

Figure 1. Illustration of Health 4.0 Concept Source: Pang et al. (2018) (with permission)

\section{Challenges of Health 4.0}

There are many facets of challenges in terms of the unit of analysis of the Health 4.0 concept. Although focusing on the concept with the lens of industrial revolutions, not only in one unit but as a philosophy inholding individual, institutional, societal levels (United Nations, 2006); enables us to see the determinants and the big picture, itself conjointly based on a holistic approach. 
Table 2

Challenges of Health 4.0 on levels

\begin{tabular}{|c|c|c|}
\hline Challenges & Details & Unit of Level \\
\hline Exchange and security of data & $\begin{array}{l}\text { Regulation and standards to be set } \\
\text { - governance and liability issues } \\
\text { - the contribution to the development of } \\
\text { sustainable health programs }\end{array}$ & Society \\
\hline Demographic developments & $\begin{array}{c}\text { Decentralization in Healthcare } \\
\text { - hospital beds in decline } \\
\text { - the number of surgeries increasing } \\
\text { - the increasing number of patients are } \\
\text { being treated in day clinics, their homes, } \\
\text { and over the internet. }\end{array}$ & Society/ Institutional \\
\hline $\begin{array}{l}\text { e.g., IoT Devices (Healthcare } \\
\text { Information Technologies) }\end{array}$ & $\begin{array}{c}\text { Trust, Accuracy and Suitability Issues } \\
\text { - whom to trust? (internet or doctors) } \\
\text { - more and more electronic devices are } \\
\text { sold to measure fitness and well-being, } \\
\text { - the number of health and wellness } \\
\text { applications increasing, } \\
\text { - usage of apps is rising, but the trust is } \\
\text { being questioned. }\end{array}$ & Institutional/Individual \\
\hline Lack of Awareness & $\begin{array}{c}\text { Education and training needed } \\
\text { - patient education on self-management } \\
\text { of health, illness, wellness, etc. } \\
\text { - setting up new health goals, } \\
\text { - patients are to be ready to understand } \\
\text { and consent to new practices and } \\
\text { responsibilities } \\
\text { - healthcare providers to be trained to } \\
\text { serve under new technologies }\end{array}$ & Individual/Institutional \\
\hline Concern of Manageability & $\begin{array}{c}\text { A manageable future } \\
\text { - next-generation mobile network } \\
\text { services (5G) settlement. } \\
\text { - all stakeholders' ultimate gain so, a } \\
\text { collective approach is needed, } \\
\text { - economic opportunities vs. socio- } \\
\text { economic challenges. Which comes first? } \\
\text { - healthcare spending average ratio of } \\
\text { GDP is increasing }\end{array}$ & Society/ Institutional/ Individual \\
\hline
\end{tabular}

Source: Adapted from Thuemmler and Bai (Ed. 2017), Health 4.0: How Virtualization and Big Data are Revolutionizing Healthcare (Thuemmler and Bai, 2017), and created by the authors.

As those challenges may refer to an information revolution, e.g., with the help of digital technologies, our way of purchasing has changed (having groceries delivered to the door, investing money through an app., etc.).

We stand as the touchstone of all changing technologies; for us, this means achieving better as we do things for final users. The better we accommodate the challenges into opportunities, the better we manage the new requirements as in multifaceted levels mentioned above, on individual, institutional, and societal levels. Besides, challenges among all those levels can be overcome through segmentation such as technical, ethical, legal, political to 
frame the effects and the frameworks of manageability. For this reason, it is not only the focus of computer or engineering science but also social science such as business administration, sociology, psychology, public administration, communication and education that should be a research focus in order to gain from the possible benefits. Some of the benefits on a societal level can be foreseen, such as using new technologies, even a promising increase in voting participation or citizen engagement, meaning more direct decision making (Manville and Ober, 2019). On the other hand, the challenges of big data on manageability concern still is a debate (Stevens and Wernimont, 2018)

\section{Integration of Health 4.0}

Given the general information of Health 4.0 challenges as above, the integration framework is very much on a similar topic. Basically, to overcome the obstacles turning to opportunities and gain benefits embedded in working by segmenting (e.g., system approach). It is not the authors' aim to make a strategic plan or form a strategy for integration; however, by doing so, the main logic of the Health 4.0 concept can be framed to help to ensure the urgency at first glance and sustainability later.

Technology has made many efforts in the past decade through all industrial revolutions that enlighten AI, robotics, IoT, automation, computing, information systems, etc. As technology is a unique specialization, integration should be done via politics, the legal system, and a cultural basis. Knowing that this is not easy to apply in other segments and levels, taking baby steps could be a strategy. Although the change in manufacturing fact of Industry 4.0 is changing rapidly, Health 4.0 is in the early stages; therefore, it should be very well designed and put forth. Health 4.0 depends on the issues at the societal level, governance, and legal issues needed to be solved. Today, the number of the aging population on one side and the increasing number of mobile device users (internet) on the other, are forcing governments to act on the advantages considering Healthcare's expanding cost. Besides, the exchange of data and data security concerns people, sectors, and society. Hence, the boundaries are to be identified, and requirements of legal settlements propounded affecting from macro to micro-levels. As those levels are interdependent, they can be concluded as technical, legal, and political.

Education is another dimension combining all levels of interest. Universities and institutions could be the accelerator of forming frames, accessing, implementing the process of the revolutions. With the help of the knowledge gathered from academic research, the development of strategy and design process of Health 4.0 can be enabled. The produced information needs to be shaped by how, when, and to whom uses it effectively Healthcare has also become one of the pioneer programs in many aging countries as it can account for the necessity of this era. To give an example; in Turkey, a recent doctoral scholarship has been announced covering the programs of eldercare, elderliness, and geriatrics (Higher Education Council 
of Turkey, 2019). By doing this, the awareness of the reality of healthcare under the Health 4.0 lenses will be clarified by qualified staff. However, we also know that education must be multifaceted, such as staff, practitioners, academics, patients, and society at a wider level. In sum, Health 4.0 is not a trend but a massive change that we soon are going to face; for this reason, we need to push the awareness levels as high as we can regarding the resistance that always comes with change.

This article aims to reveal two points: a- to clarify the concept and why it should be adopted as a philosophy and b- to review the drivers and challenges of Health 4.0 by identifying the status quo of the concept in Turkey. Further, the authors' aim is also to reveal the embedded meaning Health 4.0 and to envision the future research direction.

\section{Methodology}

\section{Methods Study 1}

The purpose of Study 1 is to assess RQ1 and the roots for RQ2 above via IoT stand examples via two written vignettes, which intrinsically aims to reveal the embedded awareness of the concept. This work seeks to address the aforementioned concept and to assess the dependent variable awareness of Health 4.0, via constructed scenarios. Employing the Vignette $\mathrm{m}$ ethodology is chosen as an effective method for measuring events on an individual's perceptions. Vignettes enhance researchers to reach the intentions, attitudes, and behaviors; in this case, awareness of the Health 4.0, can be explored through participants' responses (Atzmüller and Steiner, 2010).

In the natural setting of this work, a mixed model qualitative research design has been chosen. The data gathered from Vignette 1, fundamentally had the roots for Vignette 2. In terms of the vignette methodology, both scenarios may refer to policy conducting type. Depending on a priori knowledge, the authors would like to have a clear understanding of the factors and their level of importance in terms of creating a societal engagement framework. If one can reveal the observed effects, eventually, work as a sequence in the decision-making process, reminding that qualitative philosophy's main aim is not to reach fully generalizable results (Taylor, 2005) (Hughes and Huby, 2002).

\section{Participants and Procedures}

The sample of this work is six participants. Although the number of participants is adequate for this form of work, it can be maximized for further analyses. Given the notion of "the quality of the data obtained is dependent upon the respondent" (Cavanaugh and Fritzsche, 1985), authors have gathered the data from the sampling that match this study's purpose. For 
instance, our sample consists of 3 academics, two doctors, and one bank manager who all have senior parents (min. +65 aged) and personally immersed with the given scenarios.

Furthermore, to overcome validity issues, we paid attention to the below recommendations from vignette literature:

- $\quad$ the participants chosen for the study are familiar with the situation presented; otherwise, responses may be artificial (Aiman-Smith, Scullen, and Barr, 2002),

- $\quad$ they are willing to provide information,

- " "Actual derived cases" or "more lifelike scenarios" to provide details to reach realistic factor levels (Shepherd and Zacharakis, 1999).

Following the information given for the scenario, participants were allowed to express themselves, reflecting their intentions and feelings evaluating the real-life situation via indepth interviews all lasting one session, an average of 30 mins. The data gathered from participants are coded and defined as drivers and challenges. The segmentation of challenges can be addressed as technological, legal, societal, security (Study 2).

\section{Material and Measure}

To be able to understand the main dimensions of the Health 4.0 ecosystem and the most important factor for the respondents to design a new health revolution engagement in realistic conditions, two vignettes were intended for providing general information about what is to be done in the future. Materials are in the Appendix.

\section{Results}

According to the majority of the participants ( 4 of 6 ), the system is approachable due to the global technology level. However, the awareness of the aging population and forecasting the possible precautions revealed by the participants cannot be generalized to the population of Turkey. Some critical statements regarding RQ1 as following:

P1 (Male-MD): “...I believe that this can be done with education. We have patients who cannot even express what is wrong with them... because they are living with their children who are taking care of them. Sometimes the treatment is not solely the patient's decision, but their children's'. It is so cultural as something must change in the culture..."

P3 (Female- Academician): “... when I read the scenario, I said to myself as I have seen it before...many times, in series or movies, particularly. I really wish to have this system in Turkey as I have pretty much the same concerns. When you get older, it feels like everyone around you is falling apart as thinking about how much bad news (esp. cancer) I have heard 
in the last five years... I also think that's why everything matters after it becomes a crisis..."

\section{Methods Study 2}

To clarify RQ2 and to consider how the Health 4.0 concept is embedded with many criteria, the authors decided to examine the qualitative data gathered from Study 1 to form knowledge of the context of this work. Hence, the decision-making process that has occurred in Health 4.0 is complex and challenging, the core context being usual human activity that helps to make decisions based on choosing, ranking or sorting alternatives (Zhang, Ju, and Liu, 2017). The decision-making procedure involves finding the best alternative, choice, option, action, or ranking of the alternatives when there are many (Kuo, 2017). Given the information above, the decision making process is chosen in this work to provide decision support through the development of the knowledge of the context Health 4.0 and to excavate the embedded knowledge to be able to establish a new area of expertise- the Health 4.0. While researching real-world applications of multicriteria decision making/aid works, MACBETH (Measuring Attractiveness by a Category-Based Evaluation Technique) method which has formerly applied, aiming at relaunching socio-economic development inside of a European Commission (MEANS- Hainaut case), was precisely chosen for this work (Bana E Costa and Vansnick, 1997; Bana E Costa et al., 1999).

\section{Procedure}

By using MACBETH, the strengths and weaknesses of the novel concept via individualspecific judgments to institutional and societal levels achieves a strong profile in terms of any potential engagement process. In doing so, analyzing in a multicriteria method, results would help to recheck and undermine the current debates around the Health 4.0 concept, helping to form many applicability levels in the future.

Based on the data gathered from the in-depth interviews of the first scenario, we would be able to underline repeatedly given statements on similar issues which would enable us to segment main criteria such as confidentiality issues, security issues, legal level issues, societal issues, manageability issues.

\section{Material and Measure}

The MACBETH method was developed in the 1990s by C. A. Bana e Costa, J. C. Vansnick, and J. M. De Corte. The method has emerged with the aim of creating a quantitative decision-making technique based on the qualitative judgments of decision-makers. The question in the minds of the researchers who developed the method was how to put forward a scale that would indicate the preference levels of decision-makers among options without forcing them to indicate the preferences with numbers. Thus, the MACBETH method, based 
on semantic judgments such as "weak", "strong", emerged in binary comparisons (Y1ldırım and Önder, 2015). The first software for the method was developed in 1997 by J.M. De Corte (Kundakç1, 2016).

The MACBETH method is different from other MCDM methods while making comparisons based on qualitative values instead of quantitative values. This approach requires discretionary information for binary comparisons. Paired comparisons of criteria based on qualitative values. The relative weights of the criteria can also be determined. While the qualitative information determined by the decision-maker is entered into the M-MACBETH program, the software system makes a verification of the consistency of the qualitative evaluations entered and offers proposals to resolve them if there are inconsistencies between the entered qualitative values (Ercan and Kundakçı, 2017). MACBETH has similarities with techniques such as AHP from the user perspective. Both methods are based on the results of binary comparisons. However, the AHP method uses ratio-scale while MACBETH method uses interval-scale (Y1ldırım and Önder, 2015; Cevizci and Kayacan, 2019).

Decision-makers make decisions, about the difference in attractiveness between two stimuli that have seven categories, one by one on the semantic scale. It is desirable that these are extreme (extremely strong), very strong, moderate, weak, very weak, strong, and no, arranged in descending order of importance. The meanings of these seven semantic scales are as in Table 3. Performance metrics are generally qualitative judgments that are proportionally quantified on a $0-100$ scale. Criterion weights can be determined by applying the MACBETH method, which is based on the binary comparison query mode. It helps decision-makers to rank alternatives based on the overall measure of the relatively weighted attractiveness of alternatives according to various decision criteria (Karande and Chakraborty, 2014).

Table 3

Semantic scale of MACBETH

\begin{tabular}{lcc}
\hline Semantic Scale & Equivalent Numerical Scale & Significance \\
\hline Null & 0 & Indifference between alternatives \\
Very Weak & 1 & An alternative is very weakly attractive over another \\
Weak & 2 & An alternative is weakly attractive over another \\
Moderate & 3 & An alternative is moderately attractive over another \\
Strong & 4 & An alternative is strongly attractive over another \\
Very Strong & 5 & An alternative is very strongly attractive over another \\
Extreme & 6 & An alternative is extremely attractive over another \\
\hline
\end{tabular}

If the comparison using seven semantic scales is unreasonable, the decision-maker has the freedom to select more than one ordered category. Decisions provided by the decisionmaker are checked for consistency. If the judgments presented are found to be inconsistent, the M-MACBETH software proposes changes to make the decisions consistent. Consistent decisions are then translated into proportional quantitative scales. For the conversion of ordered scales into quantitative MACBETH scores, a mathematical operation is done (Kabalak et al., 2014). 
The steps to be followed while solving the problems with the MACBETH method can be summarized are as follows:

Step 1: Criteria are determined and shown in the value tree structure.

Step 2: After creating the value tree, alternatives are determined. Then, the possible performance of alternatives based on a specific criterion. The sequential performance levels showing are defined. Minimum two reference levels, upper reference (good) level, and lower reference (neutral) level need to be defined. On the MACBETH scale, the upper reference level gets 100 points, while the lower reference level gets 0 points. Here, 100 does not represent the best possible score, and 0 does not mean the worst performance of the alternative for a given criterion.

Step 3: The ( $\mathrm{m} \times \mathrm{m})$ dimensional matrix is created for the alternatives. $\mathrm{m}$ shows the number of alternatives to be evaluated based on the specified criteria. Within the matrix, alternatives are ordered from left to right according to their importance. This is done to measure qualitative performance levels and to convert quantitative performance levels into the MACBETH scale. The same procedure is applied for the criteria.

Step 4: Paired comparisons are made for criteria and alternatives. In the MACBETH method, the seven-category scale shown in Table 3 is used for evaluations.

Step 5: The consistency of the judgments made by the decision-maker is checked. If the judgments given are found to be inconsistent, the M-MACBETH software indicates possible changes that need to be made.

Step 6: Consistent judgments expressed according to the MACBETH scale are converted into an appropriate numerical scale using linear programming models, and scores regarding the preferability of alternatives are obtained.

Step 7: Finally, obtained alternative scores are added up by multiplying them by the criterion weights. Thus, the overall scores of the alternatives are calculated. According to the general scores obtained, the alternatives are ranked in descending order (Ercan and Kundakc1, 2017).

\section{Results}

Through the given procedure, the main criteria are set into four segments, with $11 \mathrm{com}$ mon statements gathered from Study 1. Criteria of this study are examined by forming a value tree as can be seen in figure 2 below: 


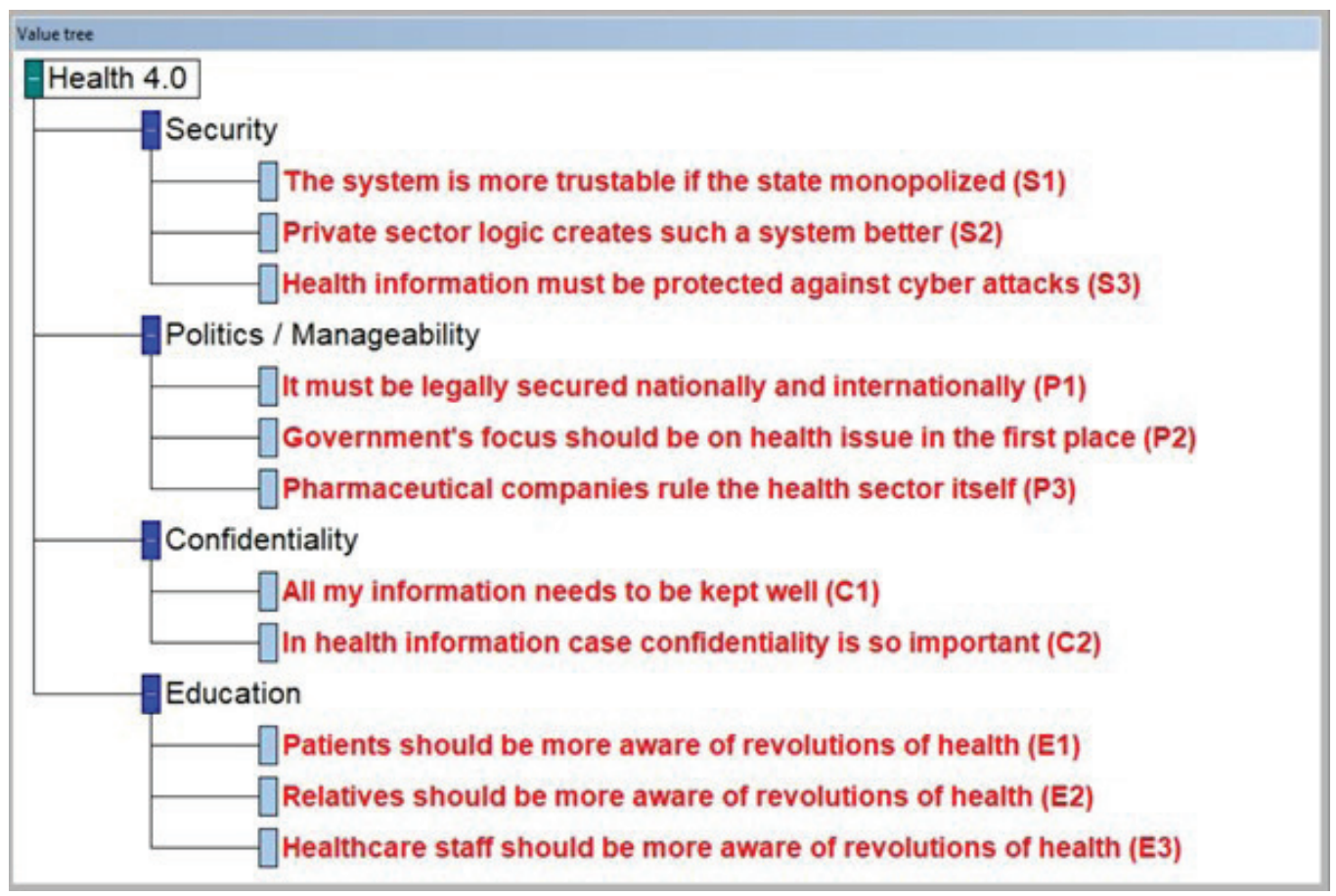

Figure 2. Value tree of the study

As seen from the chart above, after segmented under four main and 11 criteria have been examined in MACBETH by pairwise comparison. The matrix form of criteria weighting is as below in figure 3 .

\begin{tabular}{|c|c|c|c|c|c|c|c|c|c|c|c|c|c|}
\hline D & [\$1] & [53] & [E]] & [E] & [C2] & [E1] & [52] & [P1] & [C1] & {$[P 2]$} & [P3] & [ all lower] ] & extreme \\
\hline [S1] & no & weak & weak & weak & weak & weak & strong & strong & strong & strong & $\gamma$, strong & poritive & v. stieng \\
\hline [SJ] & & no & weak & weak & weak & weak & weak & moderate & moderate & strong & strong & posithve & strong \\
\hline [E3] & & & no & weak & weak & wesk & weak & weak & weak & weak & weak & positive & moserato \\
\hline$[E 2]$ & & & & no & weak & weak. & weak & weak & weak & weak & moak & ponitive & wow \\
\hline$|C 2|$ & & & & & no & weak & weak & weak & weak & weak & weak & positive & no \\
\hline [E1] & & & & & & no & weak & weak & weak & weak & weak & ponitive & \\
\hline [52] & & & & & & & no & weak & weak & weak & weak & ponitive & \\
\hline [P1] & & & & & & & & no & weak & weak & weak & positive & \\
\hline [C1] & & & & & & & & & no & weak & weak & positive & \\
\hline$[P 2]$ & & & & & & & & & & no & meak & potitive & \\
\hline$[\mathrm{P3}]$ & & & & & & & & & & & no & positive & \\
\hline [ all lower ] & & & & & & & & & & & & no & \\
\hline
\end{tabular}

Figure 3. Criteria Weights Matrix

All linguistic criteria have been assessed quantitatively, and all judgments are found consistent. As can be seen, all the comparisons in Fig. 3 above, one can compare one single 
judgment to all the others in pairwise by weighting as extreme, very strong, strong, moderate, weak, very weak, and none. The criteria weights of MACBETH can be seen in Fig. 4.

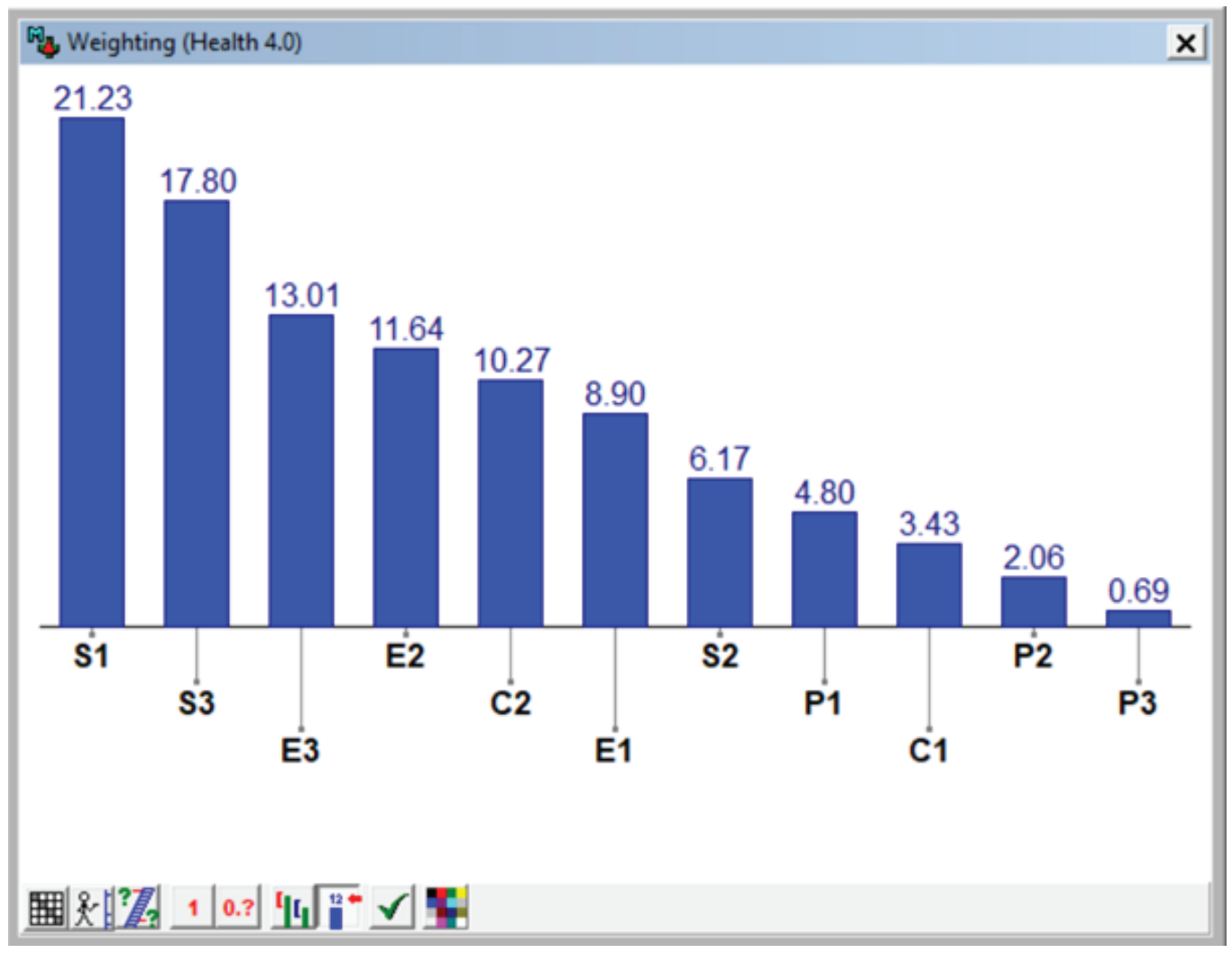

Figure 4. Criteria Weights

As shown in Fig.4 above, the most important criterion is $\mathrm{S} 1$ (\%21), while P3 is the least important (\%0.73). Security segmented criteria such as S1 and S3 are the prioritized challenges of Health 4.0 for the respondents of this study in the context of Turkey.

\section{Discussion}

Among the 11 challenges reported in Turkey, the most important criteria can be headed under security, which is also supporting the idea that Industry 4.0 is currently pertinent to the Health 4.0 concept. Prospectively, the security of health data and protection by the state-owned sector (S1 and S3) were in the top three. However, although the politics/manageability criteria were the least important, one should remember that the top-ranking criteria are required not only technical but also legal and managerial aspects. Besides, remembering that study 2 is a group decision, the ranking might not be predictable, according to the literature above. 
In this study, security, education, confidentiality, and the politics/managerial main criteria are ranked among each other. According to the results, the government has the primary responsibility in terms of regulating and managing the health system, the security of health data, and the education of healthcare providers in Turkey. These results may also be underestimated due to the current conditions of health, as the Ministry of Health is the primary regulator working with related agencies of the Ministry of Family and Social Policies. Citizens are protected by the Social Security Institution, the main body to regulate, monitor, and control is responsible for many topics from health insurance, pharmaceuticals to quality of care. Hence, any exchange done will be under the government umbrella. Observations showed that the awareness of this Health 4.0 is also expected to be included in national policies. Participants' decisions were referred to and it was stated that even awareness training was reasonably predictable with public systems. This result is contradictory to decentralization needs, as mentioned in the literature (Thuemmler and Bai, 2017). As a matter of fact, regarding cultural norms and value issues, the government is still seen as the main body of any change in Turkey. Here an interesting question comes into mind to examine in further studies, whether being the main body in health will still work in terms of personalized and precise healthcare or not. Although the paradigm is shifting to decentralization, the more the government has a hands-on approach, the more people trust in security problems.

An exciting result in terms of education; people see healthcare providers need more qualifications in health issues (E3) rather than relatives or themselves (E2). This finding stresses that qualification and training are necessary. One side of this tendency is educationally based (universities and institutions), while the other is 'a seeking vision'. This vision is societal. Creating or building a system and knowledge in furtherance, tralatitiously can be defined as hardware and software.

\section{Conclusion}

This study contributes to Health 4.0, its awareness, and the criteria involved in understanding and managing new health logic in many ways. As Health 4.0 being a new concept, the body of knowledge and state-of-art is still incipient. With our findings, the concept itself, and its implementation, the challenges are enlightened in terms of adoption. Aligned with the holistic view, the authors revealed that the challenges are agglomerated at the societal level. As the awareness is increasing in individuals, the findings support that there are concerns about the security that occurred by digitalization as in many areas. Moreover, confidentiality impairs the security concerns; and the government is seen as the regulatory and supervisory body. In opposition, when integrating Health 4.0, the governments' role ranks as the least important while intriguingly, the data is a trust issue of the government in the first place.

Besides, as a hybrid approach, the qualitative and quantitative analyses were done as the findings from the qualitative analysis exposed the data to be used in quantitative analysis. 
This methodology helped us to see the cultural philosophy on multiple levels (individual/ institutional/societal) conjointly to see the contextual characteristics of the nation in order to be able to take assertive actions.

The used methodology has some practical contributions, providing practitioners, managers, decision-makers, and leaders with some evidence that embraces the change by revealing the state-of-art and practical use of MACBETH method.

With more decision-making models, behavioral assessments will help to gain knowledge for government and practitioners in multi-disciplinary convergence. Overcoming the challenges to obtaining benefits are in the locus of academia and industrial studies and integration of all levels to engage any kind of revolution for society. In conclusion, by framing the main logic of Health 4.0 to ensure the urgency at first glance, this study would be another brick in the wall of change.

\section{Limitations and Recommendations For Further Studies}

Regarding the limitations, the participants were aware of the current security and the confidentiality debates about the concept as discussed in the literature. This presupposition might have reflected the weights of the judgments in the MACBETH approach. For this reason, the discussion of challenges revealed in this study cannot be generalized. Second, the participants' awareness of Health 4.0 is without experience, yet this is a real limitation as the decision-making process is under bounded vision.

As the integration challenges are examined in this study, the economic and socio-economic constraints were not subjected. For further studies, in terms of emerging country sampling, measuring the economic data of the resources that are being used in integration would add some insights.

Peer-review: Externally peer-reviewed.

Conflict of Interest: The authors have no conflict of interest to declare.

Grant Support: The authors declared that this study has received no financial support. 


\section{References}

Aiman-Smith, L., Scullen, S. E., \& Barr, S. H. (2002). Conducting studies of decision making in organizational contexts: A tutorial for policy-capturing and other regression-based techniques. Organizational Research Methods, 5(4), 388-414.

Alshurafa, N., Xu, W., Liu, J. J., Huang, M.-C., Mortazavi, B., Roberts, C. K., \& Sarrafzadeh, M. (2013). Designing a robust activity recognition framework for health and exergaming using wearable sensors. IEEE Journal of Biomedical and Health Informatics, 18(5), 1636-1646.

American Institution for Medical and Biological Engineering. (2019). Hall of Fame Innovations. Milestones of Innovations website, https://aimbe.org/milestones-of-innovation/

Atzmüller, C., \& Steiner, P. M. (2010). Experimental Vignette Studies in Survey Research. Methodology, 6(3), 128-138.

https://doi.org/10.1027/1614-2241/a000014

Bana E Costa, C. A., \& Vansnick, J. (1997). Applications of the MACBETH approach in the framework of an additive aggregation model. Journal of Multi-Criteria Decision Analysis, 6(2), 107-114.

Bana E Costa, C. A., Ensslin, L., Cornêa, É. C., \& Vansnick, J.-C. (1999). Decision support systems in action: integrated application in a multicriteria decision aid process. European Journal of Operational Research, $113(2), 315-335$.

Cavanaugh, G. F., \& Fritzsche, D. J. (1985). Using Vignettes in Business Ethics Research. In L.E. Preston (Ed.), Research in Corporate Social Performance and Policy (pp.279-293). Volume 7, JAI Press, Inc.

Cevizci, D. K. \& Kayacan, O. (2019). Bir Konfeksiyon İşletmesinde MACBETH ve TOPSIS Yöntemleri ile Tedarikçi Seçimi. DEUFMD, 21(62), 331-344.

Ercan, E. \& Kundakc1,N. (2017). Bir Tekstil İşletmesi İçin Desen Programı Seçiminde ARAS ve OCRA Yöntemlerinin Karşılaştırılması. Afyon Kocatepe Üniv Sosyal Bilimler Dergisi, 19(1), 83-105

Hathaliya, J. J., \& Tanwar, S. (2020). An exhaustive survey on security and privacy issues in Healthcare 4.0. Computer Communications, 153, 311-335.

Hermann, M., Pentek, T., \& Otto, B. (2016). Design principles for industrie 4.0 scenarios. 201649 th Hawaii International Conference on System Sciences (HICSS), 3928-3937. IEEE.

Higher Education Council of Turkey. (2019). YÖK 100/2000 Project Announcement. https://www.yok.gov. tr/Sayfalar/DuyuruDetay.aspx?did=863

Hughes, R., \& Huby, M. (2002). The application of vignettes in social and nursing research. Journal of Advanced Nursing, 37(4), 382-386.

Kabalak, İ., Baysal, M. E., Sarucan, A., \& Engin, O. (2016). Çok Kriterli Karar Verme Yöntemleri İle Tedarikçi Seçimi ve MACBETH Tekniğinin Bir Firmada Uygulaması". Uluslararası Katılımlı Üretim Araştırmalart Semp, 12-14.

Karande, P., \& Chakraborty, S. (2014, January). A facility layout selection model using MACBETH method. In Bali, Indonesia: Proceedings of the 2014 International Conference on Industrial Engineering and Operations Management (January 7-9).

Kundakc1, N. (2016). Combined multi-criteria decision making approach based on MACBETH and MULTIMOORA methods. Alphanumeric Journal, 4(1), 17-26.

Kuo, T. (2017). A modified TOPSIS with a different ranking index. European Journal of Operational Rese$\operatorname{arch}, 260(1), 152-160$. 
Liao, Y., Deschamps, F., Loures, E. D. F. R., \& Ramos, L. F. P. (2017). Past, present and future of Industry 4.0-a systematic literature review and research agenda proposal. International Journal of Production Research, 55(12), 3609-3629. DOI: 10.1080/00207543.2017.1308576

Manville, B., \& Ober, J. (2019). In Search of Democracy 4.0: Is Democracy as we know it destined to die?. IEEE Technology and Society Magazine, 38(1), 32-42.

Meyer, A. C., Torssander, J., Talbäck, M., \& Modig, K. (2019). Parents survive longer after stroke than childless individuals: a prospective cohort study of Swedes over the age of 65. European Journal of Public Health, 29(6), 1090-1095.

https://doi.org/10.1093/eurpub/ckz053

Michael, K., Gokyer, D., \& Abbas, S. (2018). Societal implications of wearable technology: Interpreting "trialability on the run". In Wearable Technologies: Concepts, Methodologies, Tools, and Applications (pp. 1095-1117). IGI Global.

https://doi.org/10.4018/978-1-5225-5484-4.ch050

Nair, A. \& Dreyfus, D. (2018). Technology alignment in the presence of regulatory changes: The case of meaningful use of information technology in healthcare. International Journal of Medical Informatics, $110,42-51$.

National Information Board. (2014). Using Data and Technology to Transform Outcomes for Patients and Citizens A Framework for Action. In Personalised Health and Care 2020. https://www.gov.uk/government/ uploads/system/uploads/attachment_data/file/384650/NIB_Report.pdf

Pang, Z., Yang, G., Khedri, R., \& Zhang, Y.-T. (2018). Introduction to the special section: convergence of automation technology, biomedical engineering, and health informatics toward the healthcare 4.0. IEEE Reviews in Biomedical Engineering, 11, 249-259.

Shepherd, D. A., \& Zacharakis, A. (1999). Conjoint analysis: A new methodological approach for researching the decision policies of venture capitalists. Venture Capital: An International Journal of Entrepreneurial Finance, 1(3), 197-217.

Stevens, N., \& Wernimont, J. (2018). Seeing 21st Century Data Bleed through the 15th Century Wound Man. IEEE Technology and Society Magazine, 37(4), 46-54. [8558773]. https://doi.org/10.1109/ MTS.2018.2876214

Taylor, B. J. (2005). Factorial surveys: Using vignettes to study professional judgement. British Journal of Social Work, 36(7), 1187-1207.

Thuemmler, C., \& Bai, C. (2017). Health 4.0: How Virtualization and Big Data are Revolutionizing Healthcare.

https://doi.org/10.1007/978-3-319-47617-9

Tortorella, G. L., Fogliatto, F. S., Mac Cawley Vergara, A., Vassolo, R., \& Sawhney, R. (2020). Healthcare 4.0: trends, challenges and research directions. Production Planning \& Control, 31(15), 1245-1260, DOI: 10.1080/09537287.2019.1702226

United Nations. (2006). Definition of basic concepts and terminologies in governance and publicadministration. http://unpan1.un.org/intradoc/groups/public/documents/un/unpan022332.pdf

Wehde, M. (2019). Healthcare 4.0. IEEE Engineering Management Review, 47(3), 24-28.

Xu, Y. \& Chen, M. (2017). An internet of things based framework to enhance just-in-time manufacturing. Proceedings of the Institution of Mechanical Engineers, Part B: Journal of Engineering Manufacture, 232(13):2353-2363.https://doi.org/10.1177/ 0954405417731467 
Xu, L. D., Xu, E. L. \& Li, L. (2018). Industry 4.0: state of the art and future trends, International Journal of Production Research, 56(8), 2941-2962.DOI: 10.1080/00207543.2018.1444806

Yang, H., \& Cui, Z. (2018). Unique journal: Bio-design and manufacturing. Springer.

Yıldırım, B. F., \& Önder, E. (2015). Işsletmeciler, Mühendisler ve Yöneticiler için Operasyonel, Yönetsel ve Stratejik Problemlerin Çözümünde Çok Kriterli Karar Verme Teknikleri. Dora Yayınevi. Bursa.

Zhang, W., Ju, Y., \& Liu, X. (2017). Interval-valued intuitionistic fuzzy programming technique for multicriteria group decision making based on Shapley values and incomplete preference information. Soft Computing, 21(19), 5787-5804. 


\section{APPENDIX}

Definition V1: Imagine that you have concerns about your 77-year-old mother, who lives alone outside the city. If she falls at home and her phone isn't there, how will she call you or her neighbor or $112 *$ and ask for help? To prevent a situation given, a device was made with the size of a car key and with a button easily pressed (hence can be hung lengthwise like a necklace). It could also measure movement and, at the same time, understand the fall. In case of danger (sensation of fainting, falling, injury, etc.) when the person presses the button, the staff of the insurance company OR 112 is immediately contacted and the ambulance comes to rescue your mother as soon as possible ...

This device also applies to the sensation of blood pressure, body temperature, or heart rhythm.

Definition V2: Your father, who had to live alone after losing your mother, has a sleep apnea problem. When you first get up in the morning, as because you can't be there for reasons such as living in a different city and your work intensity, your first job is to call and check on him. This is both an indication of your helplessness and means that you live with constant anxiety in your brain through your daily routine. One day a friend speaks of a system, a system established for the elderly and those with health problems. A system that changes according to the distress of the individual but makes measurements with wearable devices and gives direct information to the home-hospital or home-rehabilitation center or home-health centers when a specific limit is exceeded ... A system is taking the signal from the individual and making an evaluation spontaneously, warning even the individual interferes in situations of danger, progressing as soon as possible ...

You told your friend: "I couldn't get any good news from you today, and you immediately contacted the company/ies to join the system.

*Version of 911 in Turkey. 
